Viewpoint

\title{
How Should We Respond to the Global Pandemic: The Need for Cultural Change
}

\author{
Ben Gray
}

check for updates

Citation: Gray, B. How Should We Respond to the Global Pandemic: The Need for Cultural Change. Challenges 2021, 12, 8. https://doi.org/10.3390/ challe12010008

\section{Academic Editors:}

Palmiro Poltronieri and Susan

L. Prescott

Received: 21 December 2020

Accepted: 25 February 2021

Published: 3 March 2021

Publisher's Note: MDPI stays neutral with regard to jurisdictional claims in published maps and institutional affiliations.

Copyright: (C) 2021 by the author. Licensee MDPI, Basel, Switzerland. This article is an open access article distributed under the terms and conditions of the Creative Commons Attribution (CC BY) license (https:// creativecommons.org/licenses/by/ $4.0 /)$.
Primary Health Care and General Practice Department, University of Otago, Wellington 6021, New Zealand; ben.gray@otago.ac.nz

\begin{abstract}
The Covid pandemic has had a terrible effect on the world and government responses have been described as "Catastrophic Moral Failure". The approach of bioethics of developing "normative ethics" has provided frameworks on how to act but despite the fact that we knew what to do to prevent the pandemic, we did not do it. In this paper I argue that ethics is culture bound: it is the stories that "we" live by. I illustrate this with examples of cultures with differing values that were developed as a result of the particular circumstances of those cultures. I then argue that after World War 2 in response to the risks of further large wars and atrocities, work was done to further establish a "global culture" and a detailed normative ethical framework was developed by negotiation through the United Nations for that "culture". Whilst this approach has been necessary, it has not been sufficient. I argue that we need to reframe the approach as one of achieving cultural change rather than complying with ethical norms. Some societies that were unable to adapt to changed circumstances failed to survive, others failed to thrive. A similar fate awaits the whole planet if we cannot change the stories we live by.
\end{abstract}

Keywords: bioethics; culture; United Nations; multilateralism

\section{Introduction}

The Covid-19 pandemic has had a terrible effect on the world. To date (4 February 2021) there have been $104,866,737$ cases and 2,276,009 deaths [1]. It has resulted in a loss of 7\% global GDP amounting to US\$ 6 trillion [2] (p. 24). This was not an "Act of God", we knew that this was coming. There have been twelve different panels or reports to the World Health Organization discussing the risks of pandemics [2] (p. 13). We knew how to contain outbreaks of new infections and stop this developing into a pandemic but failed to act. The USA in particular was judged in 2019 to be the best prepared to respond to a pandemic [3], but has failed abysmally. The manner of distribution of vaccines against Covid-19 has been described as a "Catastrophic Moral Failure" by Dr. Tedros Adhanom Ghebreyesus secretary general of the World Health Organization [4]. The Independent Panel on Pandemic Preparedness and Response has said:

... we have failed in our collective capacity to come together in solidarity to create a protective web of human security... Only the application of principles of universality and equity will be sufficient to enable the world to come out of this crisis together [2] (p. 4).

This is a global ethical issue but how do we "do" ethics? It is not enough to analyze problems to determine what is right. In this case we knew what the right thing to do was but did not do it. I will argue that the normative approach to "doing" ethics has significant weaknesses at the clinical and national level and that an approach based on a presumption of different values and beliefs and negotiation to reach agreement is more helpful at this level. I will then examine how this might be developed further on a global level. 


\section{Ethics}

There is a significant emphasis in the bioethics literature on normative ethics which is defined by Beauchamp and Childress as "General normative ethics attempts to answer the question, Which general moral norms for the guidance and evaluation of conduct should we accept, and why" [5] (p. 1) The premise is that having established what moral norms we should accept, that clinicians in practice, or governments making decisions, or global bodies like the World Health Organization and the United Nations can rely on those norms to develop their responses.

\section{Normative Ethics}

A crucial and little examined word in the definition of normative ethics is "we": "Which norms ... should we accept". The "we" clearly includes the authors but who else does it include? They go on to assert that there is a "Common Morality" that is "the set of norms shared by all persons committed to morality ... it is applicable to all persons in all places" [5] (p. 3). The "we" clearly cannot include people that they have had no contact with, how would they know whether they agreed with this analysis? Yet they proceed to assert that it applies to all people. Veatch [6] expressed this another way in his discussion of the foundations of bioethics. He discussed a case of futile care in a child where the attending physician asserted that it was morally wrong to treat the child, and the mother insisted on continuing treatment.

I would have disagreed with his implication that one could prove a physician's behavior is morally right by appealing to the consensus of physician opinion. Even if all physicians throughout history have believed some behavior is morally right, that does not make them right. Had he then cited the opinion of a religious group or a national court or the International Court of Justice, I would have been left with the same question: how do we know a position in biomedical ethics is right just because some group or another approves? (p. 206)

In other words, on what basis can the doctor's decision be accepted as superior to that of the parents?

Normative ethics is very useful at describing what "we" do, and for many issues there is no disagreement. A value of studying and debating normative ethics is that in the process of discussing a topic a community of people can reach agreement which can then be implemented. It is problematic depending on the process that was used to determine what the norm should be. If the process is distorted by people in power to protect their power it is less useful, if it uses a process of trusting compromise (see Weinstock for a detailed discussion of this [7]) then it will be more safely applicable.

At the clinical level, the clinical practice implied by applying normative ethics is a paternalistic doctor centered approach: the doctor considers the moral dilemma according to normative ethics (or seeks input from a bioethicist) and decides what is the right thing to do. If the patient disagrees then they are provided with education to understand what the right course is and why. This approach was challenged in 2002 by Stewart et al. in their book "Patient Centered Medicine" [8], where they argued that this doctor centered approach was wrong and that more attention needed to be paid to the patient's views. Applying normative ethics to clinical practice is more likely to be effective in a culturally homogeneous setting, where there is a higher likelihood that "we" includes both the patient and the doctor. In countries with high ethnic diversity it is likely that there will be a greater divergence between the patient and the doctor. This is underlined by the extensive literature on cultural competence, much of which has come out of culturally diverse countries like the USA [9], Canada [10], Australia [11], and New Zealand [12]. This literature emphasizes including the patient's beliefs and values in the whole process of the consultation [13] and the importance of clinicians recognizing their implicit bias [14]. The goal of a consultation is to reach an agreed management plan. In New Zealand, the Health Practitioners Competence Assurance Act 2003 [15] requires three things of health practi- 
tioners; clinical competence, cultural competence, and ethical conduct. An understanding of normative ethics does not alone enable clinicians to make ethical clinical decisions.

At a national policy level New Zealand has recently adopted research ethics guidelines that explicitly argue that for New Zealand research there are two sets of principles that might apply, "bioethics principles" and "Te Ara Tika (literally the right path) principles". The Te Ara Tika principles come out of "Te Ara Tika: Guidelines for Māori Research Ethics: a Framework for Researchers and Ethics Committee Members" [16], which was produced for the Health Research Council by a group of Māori scholars who argued that conventional bioethics principles did not align entirely with the research principles that Māori believed were important. Whilst there is significant overlap between the principles there are some notable differences. For example:

Manaakitanga

Manaakitanga refers to caring for others, nurturing relationships, and being careful in the way we treat others. Aroha [respect, love], generosity, sharing, and hosting are essential parts of manaakitanga, as is upholding the mana [prestige, authority, control, power, influence, status, spiritual power, charisma] [17] of all parties.

Manaakitanga relates to cultural and social responsibility and respect for people. This value requires an understanding of the appropriateness of privacy and confidentiality, to prevent harmful effects from disclosure of information, prioritise collective participation in establishing the goals and benefits of a research proposal and empower research partnerships.

As well as gathering data, researchers should learn to collaborate with and to give back to the community (e.g., through koha [gifts) and sharing ideas].

They also asserted that the community being researched should be involved throughout the research process, from the decisions about what topic to research, how to design the study, doing the study and disseminating and acting on the results. This is an expectation that research will be done with them to help them solve their problems, not done to them on problems identified by others. There is considerable alignment between Te Ara Tika and similar documents from Aboriginal and Torres Strait Islanders in Australia [18] and First Nations people in Canada [19]. Research in New Zealand is not considered ethical unless it has considered both the traditional bioethics research principles as well as the Te Ara Tika principles, particularly if the research involves Māori subjects. Just applying "normative" ethical principles is no longer acceptable.

At an international level, Goold et al. [20] edited a book where they sought legal commentary from 23 countries across five continents as to how their countries would have addressed cases of futile care in young children, based around the scenarios of the Charlie Gard and Alfie Evans [20] (p. 1) cases in England. In short there was no agreement. Some countries gave all the decision making to parents, some relied on a more communal decision making, some prioritised sanctity of life above everything else, others were concerned about the harms of ongoing futile care. If there is a normative ethics why is it that there was so much variation in the way countries addressed this problem?

In all these examples culture interacts with ethics, so I will now address my understanding of culture.

\section{Culture/Stories}

In his book Sapiens [21], and Homo Deus [22] Harari develops his thesis that humans differ from great apes because of abstract thought, language, and shared stories that enabled them to live in larger groups.

Broadly the stories fell into three groups:

1. Stories that explained the world; where food was to be found, when to plant crops according to season, how to catch fish, how to use tools. These stories in the modern world are now largely the domain of "science" although there are many other traditions that impact on these stories. 
2. Stories that were developed to enable living together in larger groups. For example, money was developed to enable trade. Prior to that bartering was the means of allowing people to develop specialised skills, which had significant limitations. Initially the Romans and over time the whole world agreed on this story; that symbols of value "money" actually represented that value.

3. Stories describing "right behaviour".

MacGregor in his book "Living with the Gods" develops this idea and quoting Durkheim asserts that "the stories are the society" and that "If ... we lose or forget them, in a very real way we, collectively, no longer exist" [23] (p. xii).

What they are both describing here is society or culture. It aligns closely with Geertz's definition:

The first of these is that culture is best seen ... as a set of control mechanisms-plans, recipes, rules, instructions (what computer engineers call "programs") for the governing of behavior. The second idea is that man is precisely the animal most desperately dependent upon such extragenetic, outside-the-skin control mechanisms, such cultural programs, for ordering his behavior [24] ( $p .44)$.

There are many other definitions of culture, but Matsumoto's aligns closely with what Harari is describing

"a dynamic system of rules—explicit and implicit-established by groups to ensure survival, involving attitudes, values, beliefs, norms, behaviours, shared by a group, but harboured differently by each [individual] within the group, communicated across generations, relatively stable but with the potential to change across time" [25] (p. 24).

Ethics is the study of "right" behaviour. Harari's analysis is that ethics is by definition cultural; it describes the agreed right behaviour of the cultural group that espouses it, and that the shared stories of the cultural group are for the purpose of enabling people to live together, thrive and survive. It is in this setting that the concept of normative ethics may be helpful: "Which general moral norms for the guidance and evaluation of conduct should we accept, and why". The "we" are the people of the cultural group being described. The foundation of the "general moral norms" is the "rules explicit and implicit established to ensure survival ... shared by the group but harboured differently by each individual within the group .... . relatively stable but with the potential to change across time." What I am suggesting is that if the term "normative" is used then it must define who "we" are; that the ethics are normative for a particular cultural group. Also important is the insight that ethics might change over time and that they might be "harboured differently" by each individual.

\subsection{Examples of Culture}

In his three books [26-28], Diamond describes multiple case studies of societies both past and present. These stories describe how different communities lived, how they responded to crises and in some cases how they collapsed. Different communities of course developed a different set of stories to live by that enabled them to survive (or not). The clearest examples are isolated island communities, where the stories were developed with little or no input from other communities. The stories (the culture) they developed were those particularly related to surviving and thriving in the place they lived.

\subsection{The Chatham Islands/Rēkohu and Rangihaute}

The Moriori lived on Rēkohu and Rangihaute, the two largest of the Chatham Islands (a group of islands that are now part of New Zealand) [26] (pp. 53-57). These are windswept, not well suited to agriculture, but with abundant seafood. There had historically been several tribes and there had been violence between tribes but hundreds of years ago, they took a solemn vow of peace known as Nunuku's Law that banned murder and eating of human flesh forever. They lived in isolation until 1791 when the British ship Chatham arrived, and contact was made with both Europeans and Māori from the mainland of New Zealand. In 1835 a group of Māori from the Taranaki region of New 
Zealand came, and despite being outnumbered two to one slaughtered and enslaved the Moriori with no resistance. Moriori were all but wiped out as a people. The moral principle of "do not kill" worked very well until the invasion and they were unable to change their beliefs to respond to this threat and so barely survived [29].

\subsection{Tikopia}

Tikopia is an island now administered by the Solomon Islands government. It is remote, the nearest larger islands are 140 miles away and they are not much bigger [27] (p. 286). It has been occupied for the last 3000 years and supports a high population density of 800 people per square mile of farmable land [27]. They have sustained this population despite living in a cyclone zone that means their crops are periodically flattened by cyclones. They use all the available land for food production and over the years have developed a sustainable form of agriculture. At the beginning of the 17th century they killed all the pigs on the island because the pigs ate too much and damaged other crops [30]. They understood that the island can only sustain around 1200 people and to keep the population at that level they practiced population regulation described by Firth in 1929 and summarised by Diamond [27] (p. 290) coitus interruptus, abortion, infanticide, celibacy (which means not having children, they may have sex but practice coitus interruptus, abortion, or infanticide), and suicide by swimming out to sea. Most of these methods have been abandoned and instead Tikopians leave the island to live on other islands to maintain the population at a sustainable size. Many modern bioethicists would argue against abortion, and most if not all against infanticide but in the historical Tikopian context not adopting these practices could well have meant that the whole population might have died with the next cyclone [31]. However, it also illustrates that their "ethics" have changed over time; the goal of keeping the population stable remains the same but they are achieving it without abortion infanticide and suicide.

\subsection{Rapanui/Easter Island}

Rapanui/Easter Island was first "discovered" by the Dutch explorer Jacob Roggeveen in 1722. [27] (Chapter 2) It is a very remote island 2300 miles from the coast of Chile and 1300 miles from Pitcairn island. It is thought to have been populated from about 900 AD. It is famous for the enormous basalt Moai statues carved from the quarry in the centre of the island and transported around the island and erected. Some of these weigh as much as 270 tons and are 70 feet tall. The other striking feature that Roggeveen noted was that the island was desolate and virtually without trees. Archaeologists have established that the Island was originally forested and that the trees were used, and eventually used up, in transporting the Moai. This left them without trees to build canoes, and thus removed their ability to fish offshore. The Island also used to have much more abundant bird life with evidence of 25 nesting seabird species found in the oldest middens: now all extinct. When James Cook arrived in 1774, he described the islanders as "small lean timid and miserable". House sites had declined by $70 \%$ from the peak at around 1400-1600. The people from Rapanui lived by quite different stories than the Tikopia people. They were not troubled by cyclones, so their food security was more certain in the short term and they spent more of their resources building the statues. This way of living thrived for several hundred years but ultimately collapsed due to a lack of sustainability, and an inability to adapt as the conditions changed.

An important issue that is illustrated by these three examples is the importance of leadership. In the Chatham Islands Nunuku was clearly an important leader who convinced the population that violence was against their collective interests, even though there will have been some who benefitted from being more powerful and using violence. The Tikopian leader who banned pigs was similarly influential. I have no doubt that there would have been some people who enjoyed their pork but were persuaded to forgo it for the benefit of the collective. Rapanui/Easter Island did not have leadership that was able to steer them away from the disaster of losing all their trees. 


\section{Discussion of Culture}

In prehistoric times all communities would have started as homogenous self-contained communities that shared a specific set of stories adapted to their place. Whilst these ways of living persisted in isolated island communities, people living on continents inevitably began to interact with communities that lived by different stories. Whilst some communities learned to live alongside each other despite their differences there is a long human history of violence between communities in a battle for control of resources. Where they cooperated, each culture would have changed and adapted, adopting some of the practices of the adjoining cultures. Where there was conquest the adaptation was enforced but over time there were significant shared cultural elements and some shared language. The spread of the great religions meant that the values espoused by these religions were shared by people in many parts of the world. In particular the "West" (Europe, North America, Australia, and New Zealand) is a group of cultures that share a cultural heritage and as a result share some stories. Their stories stretch back to Greco-Roman times and whilst there are significant differences between Western countries, the shared heritage means that there is also significant alignment.

Hofstede [32] and his colleagues have done extensive research on national cultures through the use of survey instruments. He defines culture as:

The collective programming of the mind that distinguishes the members of one group or category of people from others. [32] (p. 6).

Like Matsumoto he related culture with survival, the book was sub-titled "intercultural cooperation and its importance for survival". He described the idea of layered moral circles; that we each belong to many different cultures; ethnic, occupational, national, religious, and that each of these cultural groups shared values and beliefs [32] (p. 17). We are family members who speak a particular language, maybe members of a religion, a profession, a sport, or a person with a disability or minority sexual orientation. In addition, we are all citizens of a country (or more than one country), living in a region (Europe, South America) and living in the world. All of us belong to many different cultures and the stories of those different cultures not infrequently conflict. As an individual I want freedom to visit who I like and travel where I want. During the pandemic I need to balance that against the well-being of the community within which I live. Put another way, there is a different normative ethics for each of these cultures. As a doctor the way I behave around confidentiality and privacy when seeing patients is much more constrained than as a face book user with my family. Importantly during the pandemic in New Zealand, our Prime Minister Ardern exhorted us to behave as a member of the "team of 5 million" in adhering to lock down rules [33], rather than as a self-interested individual. A further example of the importance of leadership.

Some parts of the world, mostly those that are more remote, are still culturally homogeneous and maintain a way of life similar to the way they have lived for many generations. They have not needed to adapt their culture greatly to be able to "live together" with others (Japan would be a good example as described by Diamond [27] (p. 101). With the ability to travel large distances there developed interaction between cultures that were completely foreign to each other. For example, over 300 languages are spoken in London schools [34]. At this extreme, the challenge of how to live together is much greater and countries that host large numbers migrating from other places have had to grapple with minority cultural practices that are not acceptable to the majority [35]. Countries where the majority population have lived for generations have a clearer cultural starting point than countries, such as the USA, Canada, Australia, and New Zealand, where a large proportion of the population have migrated more recently, particularly if there has been migration from a diverse group of home countries [36].

There is a global culture: a set of shared stories. This has become more extensive with globalisation of trade and travel. There are international systems that are all agreed around weights and measures, value of currency, postage, air traffic control and law of the sea. There is also global bioethics discussed in detail by ten Have [37]. 


\section{Foundations for Ethics}

Talking of the foundations of ethics for long established societies is somewhat meaningless. It is like trying to describe the foundations of the culture. More useful might be to describe the ethical values of those cultures. In the New Zealand setting it has been particularly helpful for the Mãori community to describe their ethical values, to understand the overlap, but also the differences with "Western" values. The process of describing the values, comparing them and deciding on how to move forward, is comparable to the framework for provision of cross cultural clinical care [13].

For "new" cultures it is much more meaningful. A good example is Fisher's study comparing the values of the USA and New Zealand [38]. He notes that both societies were settler societies who chose to move to their new country because they were unhappy with the circumstances that they travelled from. They interacted with the native populations and developed ways of living. On the face of it the countries might have been expected to develop along similar tracks. His hypothesis was that the founding values of the two societies were quite different; the USA was founded on the principle of "Freedom" and New Zealand on the principle of "Fairness" He describes the development of both countries to illustrate his hypothesis. The USA explicitly described the values of the country first by their declaration of independence [39] and then by developing a constitution, which has remained a central part of their "story" until today. From this perspective it is hardly surprising that an ethical framework from the USA would have autonomy as one of its foundational (if not the foundational) elements [5]. Whilst New Zealand does not have a constitution it views its founding document as the Treaty of Waitangi which was an agreement between the Crown and Māori [40] of how the two peoples were to live together, which was then breached over the following years. The Māori renaissance over the last thirty years has been based on the fact that Māori have not been treated fairly and there has been significant reparations and apologies made to try to resolve these breaches [41]. It is not surprising that New Zealand has a significant emphasis on equity of outcomes, particularly in health [42].

\section{Developing Global Culture and Bioethics}

The World Wars highlighted the need for a new system for people to be able to live in the world together. It was widely recognised that the belief in superiority of nations/races and the legitimacy of using power to resolve difference were behind these major conflicts and that unless there were changes then similar conflicts would happen again. To describe this in cultural terms there was an understanding that survival was under threat as a result of wars and the presumption that some people were superior to others, and that approaches limited to the cultures of nations could not address those threats. A new set of values needed to be developed that reflected the needs of all people to be able to survive and thrive. After much negotiation the United Nations was formed, with a charter [43] (1945) signed by all member states that started with the first article:

To maintain international peace and security, and to that end: to take effective collective measures for the prevention and removal of threats to the peace, and for the suppression of acts of aggression or other breaches of the peace, and to bring about by peaceful means, and in conformity with the principles of justice and international law, adjustment or settlement of international disputes or situations which might lead to a breach of the peace;

The next development was the Universal Declaration of Human Rights 1948 (UDHR) All UN member states have ratified at least one of the nine core international treaties and 80 percent have ratified four or more [44]. This established the principle that all humans are of equal value:

\section{Article 1.}

All human beings are born free and equal in dignity and rights. They are endowed with reason and conscience and should act towards one another in a spirit of brotherhood.

Article 2. 
Everyone is entitled to all the rights and freedoms set forth in this Declaration, without distinction of any kind, such as race, colour, sex, language, religion, political or other opinion, national or social origin, property, birth or other status. Furthermore, no distinction shall be made on the basis of the political, jurisdictional or international status of the country or territory to which a person belongs, whether it be independent, trust, non-self-governing or under any other limitation of sovereignty [45].

More recently the Universal Declaration on Bioethics and Human Rights (UDBHR) was passed by acclamation by the UNESCO's general conference on 19 October 2005 [46], and the Sustainable Development Goals were adopted by all United Nations member states in 2015 as a call to action to end poverty, protect the planet, and enjoy peace and prosperity [47].

These and all the other international agreements are the basis of a framework of a global normative ethics. As Magnus [48] discusses, there was extensive consultation done in the development of the UDBHR, and whilst concerns were raised about whether it reflected a "Western" view of individual human rights and did not adequately reflect an "Asian" view of "holistic happiness and welfare of the total group or community to which they belong ... Despite existing controversy, ... the Declaration was nevertheless adopted unanimously by member states." [48] (pp. 37-38).

As with other cultures, it is "harboured differently by each individual within the group". It is of course only signed up to by governments rather than all the individuals in each country so the extent to which it is "harboured" is even less certain than a normative statement of a national cultural group.

However as a statements of normative ethics they have a much more secure foundation than the assertion by Beauchamp and Childress [5], that their principles apply to all people, having been negotiated and agreed at least by all, or a majority of countries in the world.

There has been considerable cultural change as a result of these declarations particularly in relation to the rights of previously oppressed people; women, racial minorities, and people with diverse sexual orientation. The extent of change has varied around the world, and it is an ongoing process. The \#MeToo movement [49] and \#blacklivesmatter [50] are clear examples of continuing change.

There has been less change in relation to the first article of the UN charter to resolve international disputes with peaceful means. There are glaring inconsistencies in appeals to these norms. The USA justified the invasion of Iraq on the basis that the leader was unstable and had access to Weapons of Mass Destruction (WMD). The use of force made things worse, there was little evidence of WMD and if that invasion was justified then China could have justified the invasion of the USA who did have an unstable leader, who indisputably had WMD. We now know that during the Trump administration there was a significant risk of a nuclear exchange with North Korea [51].

\section{Doing Ethics Differently: An Example}

As with clinical and research ethics, global ethics has a well-established normative ethics that was developed by a robust process and yet despite this it was not used as a guide to action in the pandemic. We need processes that acknowledge the gap between how people currently behave and how they "ought" to behave.

An important paper in the management of pandemics was developed out of Toronto following the SARS outbreak [52]. The authors developed a pandemic planning document that they described as an example of applied/practical ethics. They observed:

To our knowledge, no other pandemic planning process has attempted to a) develop an ethical framework to guide pandemic influenza planning and b) assess an ethical framework's robustness and resonance in the community of its intended users [52] (p. 3).

And then that:

This paper has a more narrow focus - it is an example of applied/practical ethics that attempts to introduce and articulate values that are already commonly accepted. It is not 
our intention to comprehensively defend the values in the framework, but rather to show from which areas of scholarship they were drawn, articulate their relevance to pandemic planning, and to demonstrate their discursive legitimacy through a process of stakeholder engagement and vetting ( $p .3)$.

It is arguably also an example of descriptive ethics, in that in addition to articulating commonly accepted values they also included a process of stakeholder engagement and vetting to develop a "robustness and resonance in the community of its intended users."

If the document is describing the ethical values held by that community then it is much more likely that in the event of implementing the plan that the plan will be followed. The other significant element of their plan was that there was equal emphasis between ethical values and ethical processes. They based this on the work of Daniels and Sabin $[53,54]$. They outlined an ethical decision-making process and argued that:

Stakeholders will be more able to accept difficult decisions during a pandemic influenza crisis if the decision-making process has, and is perceived to have, ethical legitimacy.

Interestingly, the Universal Declaration on Bioethics and Human Rights was adopted around the same time and included the following clause that addresses the same issue:

Article 18-Decision-making and addressing bioethical issues

1. Professionalism, honesty, integrity and transparency in decision-making should be promoted, in particular declarations of all conflicts of interest and appropriate sharing of knowledge. Every endeavour should be made to use the best available scientific knowledge and methodology in addressing and periodically reviewing bioethical issues.

2. Persons and professionals concerned and society as a whole should be engaged in dialogue on a regular basis.

3. Opportunities for informed pluralistic public debate, seeking the expression of all relevant opinions, should be promoted [46].

Modelled on this plan, New Zealand produced its own pandemic ethics planning document: "Getting Through Together" [55]. This had the same equal emphasis on ethical processes and ethical values. It was developed following wide consultation and in particular with significant input from Māori and as a result included many Māori ethical concepts. Again, according to your definition this is either a work of descriptive ethics or of normative ethics for the people of New Zealand. This document became embedded in our New Zealand Influenza Pandemic Action Plan [56] and in my view became an important element in New Zealand's successful response to Covid-19. In a recent paper [33] I described that there was a very close alignment between the content of the press releases from the Prime Minister and the Director General of Health and the values and processes described in the "Getting Through Together" document.

An abrupt cultural change was achieved in a matter of a few days from "life as normal" to the considerable social restrictions of a full lock down. In my paper [33] I describe four elements vital to achieving this:

1. Transparent decision making and full information. There were daily briefings from the Prime Minister and the Director General of Health, with extended questions from the media afterwards.

2. Good quality scientific advice justifying the options being considered, again clearly explained and discussed.

3. An ethical framework that had been developed in advance with significant consultation that used familiar terms and concepts.

4. A trusted leader in Prime Minister Jacinda Ardern.

Despite having one of the most stringent lockdowns [57], this was successfully carried out with almost no need for enforcement [33]. A particular value that was emphasised was equity of outcome, particularly for our Māori and Pacific people who were likely to be the most adversely affected part of the community in the event the virus spread [58]. It was pointed out that the elimination was the best strategy to protect these populations. 
By contrast the USA had ineffective leadership, information was variable, unclear, coming from many sources and not trusted. The science was inconsistently applied. Whilst ethical frameworks were developed, for example in relation to vaccination [59], they were unable to be implemented [60].

\section{Conclusions}

The world is facing an existential crisis at least as large as that faced following World War 2. The scale of action needed to avoid the risks to survival of pandemics, climate change, nuclear war, and inequalities is large.

The [Independent] Panel [for Pandemic Preparedness and Response] believes that the COVID-19 pandemic must be a catalyst for fundamental and systemic change in preparedness for future such events, from the local community right through to the highest international levels [2] (p. 8).

The principles on which such action should be based are well developed:

1. That everyone is born free and equal in dignity and rights [45].

2. That disputes should be resolved through negotiation without a breach of the peace [43].

3. That sustainability is a foundational principle underpinning how we live together, including addressing climate change, inequalities, poverty, life below water and on land, that can only be realized with strong global partnerships [43].

4. There must be a focus on good process [46] (article 18).

Action needs to be taken at the many levels at which culture operates, we need cultural change at all these levels.

The most important level is at the individual level. If individuals do not accept these goals, do not see them as essential for their survival, they will not elect governments with the mandate to act on these goals, and in turn the governments will not act at an international level. For example, the use of arms is embedded in the USA Constitution [61] (second amendment). If the USA public are not prepared to limit the availability of arms within their country the likelihood of them supporting a government limiting them internationally is small.

Governments need to care about these issues to be able to prioritise them high enough for action against the other priorities that they might have. The biggest problem is with governments who benefit from the current status quo, who are more interested in maintaining their power than averting the coming crises.

Governments need to support and fund the multilateral agencies. We are unable to address these problems without effective well-resourced international bodies.

Courageous leadership will be required to enable the major cultural change that is needed.

In particular the arms trade is egregious. It explicitly undermines the United Nations Charter and diverts huge resources away from more useful strategies. Diamond noted that:

Japan was the third largest economy after the USA and China, but that the USA and China devote a large fraction of their budgets to military expenditures. Japan saves itself those costs because of a clause in their constitution that reduced their armed forces to a bare minimum [28] (p. 296).

The international agencies need to function effectively. The current Security Council at the UN is problematic. It entrenches power of veto in the five permanent members of the council [43] (article 27). The permanent membership reflects the outcome of negotiations on the formation of the UN, and there is no provision for reviewing the permanent membership.

Framing these problems as ethical problems has led to the development of a normative ethics, focusing on what we should do. This has been necessary but not sufficient to achieve change. My argument is that reframing the world problems as problems needing cultural change and focusing on how we achieve change may be more productive. 
Funding: This research received no external funding.

Institutional Review Board Statement: Not applicable.

Informed Consent Statement: Not applicable.

Data Availability Statement: Not applicable.

Conflicts of Interest: The author declares no conflict of interest.

Dedication: This paper is dedicated to my mother Mary Boynton Gray (1923-2018) who attended the signing of the International Declaration of Human Rights in Paris 1948 to represent youth at the invitation of Eleanor Roosevelt.

\section{References}

1. Worldometer Coronavirus. Available online: https:/ /www.worldometers.info/coronavirus/ (accessed on 2 March 2021).

2. The Independent Panel for Pandemic Preparedness and Response. Second Report on Progress. Available online: https: / / theindependentpanel.org/wp-content/uploads/2021/01/Independent-Panel_Second-Report-on-Progress_Final-15 -Jan-2021.pdf (accessed on 2 March 2021).

3. Global Health Security Index. Global Health Security Index. Available online: https://www.ghsindex.org/ (accessed on 2 March 2021).

4. Ghebreyesus, T.A. WHO Chief Warns Against 'Catastrophic Moral Failure' in COVID-19 Vaccine Access. Available online: https: / / news.un.org/en/story/2021/01/1082362 (accessed on 2 March 2021).

5. Beauchamp, L.; Childress, F. Principles of Biomedical Ethics, 6th ed.; Oxford University Press: New York, NY, USA, 2009.

6. Veatch, R.M. The foundations of bioethics. Bioethics 1999, 13, 206-217. [CrossRef]

7. Weinstock, D. The ethics of Compromise. In Compromise and Disagreement in Contemporary Political Theory; Rostboll, C., Scavenius, T., Eds.; Routledge: London, UK, 2018.

8. Stewart, M. Patient-Centered Medicine: Transforming the Clinical Method, 2nd ed.; Radcliffe Medical: Abingdon, UK, 2003.

9. Beach, M.; Price, E.; Gary, T.; Robinson, K.; Gozu, A.; Palacio, A. Cultural competence: A systematic review of health care provider educational interventions. Med. Care 2005, 43, 356-373. [CrossRef]

10. Rosenberg, E.; Kirmayer, L.J.; Xenocostas, S.; Dao, M.D.; Loignon, C. GPs' strategies in intercultural clinical encounters. Family Practice 2007, 24, 145-151. [CrossRef] [PubMed]

11. Queensland Government. Organisational Cultural Competency Framework. Available online: http://www.health.qld.gov.au/ multicultural/contact_us/framework.asp (accessed on 12 March 2013).

12. Medical Council of New Zealand. Statement on Cultural Safety. Available online: https://www.mcnz.org.nz/assets/standards/ b71d139dca/Statement-on-cultural-safety.pdf (accessed on 3 December 2019).

13. Berlin, E.A.; Fowkes, W.C., Jr. A teaching framework for cross-cultural health care-Application in family practice. West. J. Med. 1983, 139, 934. [PubMed]

14. Shirey, T.E.; Morris, A.A. Different lenses for the same story: Examining how implicit bias can lead us to different clinical decisions for the Patient. J. Am. Heart Assoc. 2019, 8, e014355. [CrossRef] [PubMed]

15. Health Practitioner's Competence Assurance Act. In HPCAA; New Zealand Government: Wellington, New Zealand, 2003.

16. Hudson, M. Te Ara Tika: Guidelines for Māori Research Ethics: A Framework for Researchers and Ethics Committee Members; Health Research Council of New Zealand: Wellington, New Zealand, 2010.

17. Auckland University of Technology. Maori Dictionary OnLine. Available online: http://www.maoridictionary.co.nz/index.cfm (accessed on 18 December 2014).

18. Australian National Health and Medical Research Council. Values and Ethics-Guidelines for Ethical Conduct in Aboriginal and Torres Strait Islander Health Research; Australian Government: Canberra, Australia, 2003.

19. Canadian Institutes of Health Research; Natural Sciences and Engineering Research Council of Canada; Social Sciences and Humanities Research Council of Canada. Ethical Conduct for Research Involving Humans; Tri-Council Policy Statement: Ottawa, ON, Canada, 2010.

20. Goold, I.; Auckland, C.; Herring, J. Medical Decision-Making on Behalf of Young Children: A Comparative Perspective; Bloomsbury Publishing Plc: London, UK, 2020.

21. Harari, Y.N. Sapiens: A Brief History of Humankind; First United States edition; Harper, an Imprint of Harper CollinsPublishers: New York, NY, USA, 2015.

22. Harari, Y.N. Homo Deus: A Brief History of Tomorrow; First U.S. edition; HarperCollins: New York, NY, USA, 2017.

23. MacGregor, N. Living with the Gods: On Beliefs and Peoples; First United States edition; Alfred A. Knopf: New York, NY, USA, 2018.

24. Geertz, C. The Interpretation of Cultures: Selected Essays; Basic Books: New York, NY, USA, 1973.

25. Matsumoto, D.R. Culture and Psychology, 2nd ed.; Brooks Cole Publishing Pacific Grove: California, CA, USA, 2000.

26. Diamond, J. Guns, Germs, and Steel: A Short History of Everybody for the Last 13,000 Years; Random House: London, UK, 1998.

27. Diamond, J. Collapse: How Societies Choose to Fail or Survive; Allen Lane: Camberwell, Australia, 2005.

28. Diamond, J. Upheaval: How Nations Cope with Crisis and Change; Penguin UK: London, UK, 2019. 
29. Davis, D.; Solomon, M. Moriori. Available online: http:/ /www.TeAra.govt.nz/en/moriori (accessed on 20 November 2020).

30. Moore, C. Tikopia Island. Available online: https://www.solomonencyclopaedia.net/biogs/E000310b.htm (accessed on 2 March 2021).

31. Anonymous. Tikopia A Study of Small Island Survival. Available online: http:/ /www.pireport.org/articles/2003/01/08/tikopiastudy-small-island-survival (accessed on 8 December 2020).

32. Hofstede, G.H.; Hofstede, G.J.; Minkov, M. Cultures and Organizations:Software of the Mind: Intercultural Cooperation and Its Importance for Survival, 3rd ed.; McGraw-Hill: New York, NY, USA, 2010.

33. Gray, B. COVID-19 from Wellington New Zealand. J. Bioeth. Inq. 2020, 1-6. [CrossRef]

34. British Broadcasting Corporation. Languages Across Europe. Available online: http://www.bbc.co.uk/languages/european_ languages/definitions.shtml (accessed on 5 July 2019).

35. Parekh, B. Minority practices and principles of toleration. Int. Migr. Rev. 1996, 30, 251-284. [CrossRef]

36. Spoonley, P. Diverse Nations, Diverse Responses: Introduction In Diverse Nations, Diverse Responses: Approaches to Social Cohesion in Immigrant Societiesqueen's Policy Studies Series; Spoonley, P., Tolley, E., Eds.; School of Policy Studies Queen's University, McGill-Queen's University Press: Kingston, ON, Canada, 2012.

37. ten Have, H. Global Bioethics an Introduction; Routledge: London, UK; New York, NY, USA, 2016.

38. Fischer, D.H. Fairness and Freedom: A History of Two Open Societies: New Zealand and the United States; Oxford University Press: Oxford, UK; New York, NY, USA, 2012.

39. The Declaration of Independence. Available online: https://www.archives.gov/founding-docs/declaration-transcript (accessed on 10 December 2020).

40. Orange, C. Treaty of Waitangi. Available online: http://www.teara.govt.nz/en/treaty-of-waitangi (accessed on 18 December 2014).

41. Mark Derby. Story: Te Rōpū Whakamana i te Tiriti o Waitangi. Available online: https://teara.govt.nz/en/waitangi-tribunal-teropu-whakamana (accessed on 2 March 2021).

42. Sheridan, N.F.; Kenealy, T.W.; Connolly, M.J.; Mahony, F.; Barber, P.A.; Boyd, M.A.; Carswell, P.; Clinton, J.; Devlin, G.; Doughty, R. Health equity in the New Zealand health care system: a national survey. Int. J. Equity Health 2011, 10, 45. [CrossRef] [PubMed]

43. Unitde Nations. Charter of the United Nations. Available online: https://www.un.org/en/charter-united-nations/index.html (accessed on 5 July 2019).

44. United Nations. The Foundation of International Human Rights Law. Available online: https://www.un.org/en/sections/ universal-declaration/foundation-international-human-rights-law/index.html (accessed on 2 March 2021).

45. Universal Declaration of Human Rights. Resolution Adopted by the General Assembly; United Nations General Assembly: New York, NY, USA, 1948.

46. United Nations Educational Scientific and Cultural Organization. Universal Declaration on Bioethics and Human Rights. Available online: https:/ / en.unesco.org/themes/ethics-science-and-technology/bioethics-and-human-rights (accessed on 2 March 2021).

47. United Nations Development Programme. Sustainable Development Goals. Available online: https://www.undp.org/content/ undp/en/home/sustainable-development-goals.html (accessed on 18 December 2020).

48. Magnus, R. The Universality of the UNESCO Universal Declaration on Bioethics and Human Rights. In Global Bioethics: The Impact of the UNESCO International Bioethics Committee; Bagheri, A., Moreno, J.D., Semplici, S., Eds.; Springer International Publishing: Cham, Switzerland, 2016; pp. 29-42.

49. Chicago Tribune. \#MeToo: A Timeline of Events. Available online: https://www.chicagotribune.com/lifestyles/ct-me-tootimeline-20171208-htmlstory.html (accessed on 2 March 2021).

50. Black Lives Matter 2021. Available online: https:/ / blacklivesmatter.com/ (accessed on 2 March 2021).

51. Woodward, B. Rage; Simon and Schuster: New York, NY, USA, 2020.

52. Thompson, A.; Faith, K.; Gibson, J.; Upshur, R. Pandemic influenza preparedness: An ethical framework to guide decision-making. BMC Med. Ethics 2006, 7, 12. [CrossRef] [PubMed]

53. Daniels, N.; Sabin, J.E. Accountability for reasonableness: An update. BMJ 2008, 337, 1850. [CrossRef] [PubMed]

54. Daniels, N. Accountability for reasonableness: Establishing a fair process for priority setting is easier than agreeing on principles. Br. Med. J. 2000, 321, 1300. [CrossRef] [PubMed]

55. National Ethics Advisory Committee. Getting through Together: Ethical Values for a Pandemic. Available online: http: // neac.health.govt.nz/system/files/documents/publications/getting-through-together-jul07.pdf (accessed on 11 August 2013).

56. Ministry of Health. New Zealand Influenza Pandemic Plan: A Framework for ACtion. Available online: https://www.health. govt.nz/publication/new-zealand-influenza-pandemic-plan-framework-action (accessed on 13 April 2020).

57. Our World In Data. COVID-19: Government Stringency Index. Available online: https:/ / ourworldindata.org/grapher/covidstringency-index?tab=chart\&stackMode=absolute\&time=2020-01-22..latest\&country=IND $\sim\{$ NZL $\sim\{\}$ GBR $\sim\{\}$ AUS $\sim\{$ SWE $\sim$ \{\}USA\&region=World (accessed on 2 March 2021).

58. Bloomfield, A. COVID-19, 20, 21: Lessons from New Zealand's 2020 response for 2021 and beyond. N. Z. Med. J. 2021, 134, 7-8. [PubMed]

59. Schmidt, H.; Gostin, L.O.; Williams, M.A. Is it lawful and ethical to prioritize racial minorities for COVID-19 vaccines? JAMA 2020. [CrossRef] [PubMed] 
60. Jean-Jacques, M.; Bauchner, H. Vaccine distribution-equity left behind? JAMA 2021. [CrossRef] [PubMed]

61. House, T.W. The Constitution. Available online: https://www.whitehouse.gov/about-the-white-house/our-government/theconstitution/ (accessed on 2 March 2021). 